\title{
Direct Beam and Diffuse Spectral Irradiance Measurements in a Nordic Country Analyzed With the Average Photon Energy Parameter
}

Riedel, Nicholas; Thorseth, Anders; Santamaria Lancia, Adrian Alejo; Thorsteinsson, Sune; Poulsen, Peter Behrensdorff; landolo, Beniamino; Davidsen, Rasmus Schmidt; Benatto, Gisele Alves dos Reis

\section{Published in:}

Proceedings of 7th World Conference on Photovoltaic Energy Conversion

Link to article, DOI:

10.1109/PVSC.2018.8548240

Publication date:

2018

Document Version

Peer reviewed version

Link back to DTU Orbit

Citation (APA):

Riedel, N., Thorseth, A., Santamaria Lancia, A. A., Thorsteinsson, S., Poulsen, P. B., landolo, B., Davidsen, R. S., \& Benatto, G. A. D. R. (2018). Direct Beam and Diffuse Spectral Irradiance Measurements in a Nordic Country Analyzed With the Average Photon Energy Parameter. In Proceedings of 7th World Conference on Photovoltaic Energy Conversion IEEE. https://doi.org/10.1109/PVSC.2018.8548240

\section{General rights}

Copyright and moral rights for the publications made accessible in the public portal are retained by the authors and/or other copyright owners and it is a condition of accessing publications that users recognise and abide by the legal requirements associated with these rights.

- Users may download and print one copy of any publication from the public portal for the purpose of private study or research.

- You may not further distribute the material or use it for any profit-making activity or commercial gain

- You may freely distribute the URL identifying the publication in the public portal 


\title{
Direct Beam and Diffuse Spectral Irradiance Measurements in a Nordic Country Analyzed With the Average Photon Energy Parameter
}

\author{
Nicholas Riedel ${ }^{1}$, Anders Thorseth ${ }^{1}$, Adrián A. Santamaría Lancia ${ }^{1}$, Sune Thorsteinsson ${ }^{1}$, Peter Poulsen ${ }^{1}$, \\ Beniamino Iandolo ${ }^{2}$, Rasmus S. Davidsen ${ }^{2}$ and Gisele Benatto ${ }^{1}$ \\ ${ }^{1}$ DTU Fotonik, Department of Photonics Engineering, Technical University of Denmark, Frederiksborgvej \\ 399, 4000, Roskilde, Denmark \\ ${ }^{2}$ Department of Micro- and Nanotechnology, Technical University of Denmark, Ørsteds Pl., 2800 Kongens \\ Lyngby, Denmark
}

\begin{abstract}
One year of spectrally resolved direct normal irradiance (DNI), diffuse horizontal irradiance (DfHI) and global horizontal irradiance (GHI) data measured in Roskilde, Denmark are analyzed in terms of the average photon energy (APE). We show that the APE of the GHI component is characterized by spectral distributions with low standard deviations, which is consistent with the findings of previous authors. In contrast, the APE of the DfHI and DNI components show spectral distributions with higher standard deviations, which suggests that a given APE value for DNI or DfHI can represent a wider array of spectral distributions. Finally, it is shown that the DfHI APE is characterized by high energy spectral distributions, which has significance in the case of building integrated photovoltaic (BIPV) applications where the glass superstrate is colored or textured in a way that it reflects blue light.
\end{abstract}

Index Terms - Average Photon Energy, BIPV.

\section{INTRODUCTION}

At the end of 2016 the global installed photovoltaic (PV) capacity was $305 \mathrm{GW}$, which represents a $25 \%$ increase from 2015 PV capacity [1]. With billions of dollars invested in PV installations each year, the industry must consider methods for appropriately siting new PV power plants and approaches for making energy yield predictions more accurate. Since 2002, several studies have examined the average photon energy $(A P E)$ in terms of whether this metric describes a unique spectral distribution [2] - [4] and in terms of its usefulness for quantifying PV performance [5] - [7]. We place emphasis on the former topic in this paper, but also assess the impact APE has on selected PV devices, specifically in regard to building integrated PV (BIPV) installations. Previous studies that analyzed outdoor spectral measurements across locations have shown that the $A P E$ is effective at characterizing a unique spectral distribution [2], [3]. However, it has also been shown by [4] that the $A P E$ of a given spectrum may only be unique when calculated in the limited range of $450-900 \mathrm{~nm}$. This limited range is primarily due to precipitable water and aerosol fluctuations that drive absorption and scattering.

A conclusion from [2] is that spectral data from more geographically unique sites is needed in order to establish that the $A P E$ is a truly location-independent means of classifying the spectral resource. It is therefore the objective of this paper to provide an additional spectral dataset that will support the photovoltaic industry in evaluating as to whether or not the
$A P E$ is a useful parameter for characterizing the solar resource. The previous studies have focused their analysis either on the global horizontal irradiance $(G H I)$ or global tilted irradiance $(G T I)$. In addition to the spectrally resolved $G H I$, we also present the direct normal irradiance $(D N I)$ and diffuse horizontal irradiance $(D f H I)$ components with respect to their APE.

\section{METHODOLOGY}

Spectrally resolved measurements are performed for one year at Technical University of Denmark's (DTU) Risø Campus $\left(55.7^{\circ} \mathrm{N}, 12.1^{\circ} \mathrm{E}\right)$ from February 2017 to January 2018. Two diffraction grating spectroradiometers are used to directly measure the DNI and DfHI components. The instruments are manufactured by EKO, Japan, cover the range of $300-1100 \mathrm{~nm}$ using Silicon based detectors with 2048 pixels each. The full width half maximum (FWHM) spectral resolution is $7 \mathrm{~nm}$. Although a detailed uncertainty budget has not been calculated for these instruments, their accuracy has been validated both indoors on DTU Fotonik's optical bench with a FEL-type reference lamp and outdoors via an international comparison [8]. The calibration uncertainty of both instruments as reported by the ISO 17025 calibration lab is $\pm 4.2 \%$ for the $400-1050 \mathrm{~nm}$ wavelength range used in this work. The measurements are acquired every 5 minutes and the unfiltered year-long dataset contains over 40,000 spectral measurements from each instrument. A picture of the setup is shown in Fig. 1.

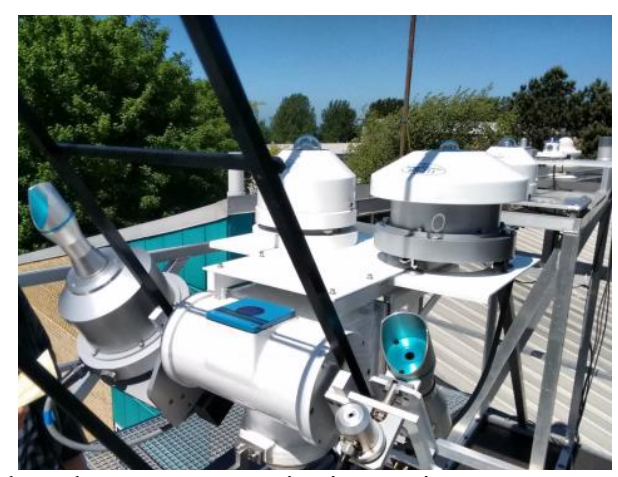

Fig. 1. The solar resource monitoring station at DTU Fotonik with instruments for measuring broadband and spectral solar irradiance. 
One of the spectroradiometers is equipped with a $5^{\circ}$ field of view (FOV) light collimation tube and thus this instrument is dedicated to measuring $D N I$. The $D f H I$ is directly measured with a spectroradiometer that has a $180^{\circ} \mathrm{FOV}$, the aperture of which is continuously shaded by a shadow ball with a $5^{\circ}$ FOV. The instruments are mounted on a two-axis tracker that has a tracking accuracy of $0.01^{\circ}$ in clear sky conditions. The alignment of the collimation tube and shadow ball is checked weekly. The sensor's optical window or dome is also cleaned weekly. The geometries of the two instruments allow for the calculation of the spectrally resolved GHI by adding the cosine corrected DNI measurement with the DfHI measurement at each wavelength as shown in Eq. [1]. Wherein $\lambda$ is the measured wavelength [nm], $D N I_{\lambda}$ is the direct normal irradiance $\left[\mathrm{W} \mathrm{m}^{-2} \mathrm{~nm}^{-1}\right]$ at wavelength $\lambda, D f H I_{\lambda}$ is the diffuse horizontal irradiance $\left[\mathrm{W} \mathrm{m}^{-2} \mathrm{~nm}^{-1}\right]$ at wavelength $\lambda$, and $\theta_{z}$ is the solar zenith angle at time of measurement.

$$
G H I_{\lambda}\left[W m^{-2} n m^{-1}\right]=D N I_{\lambda} * \cos \left(\theta_{Z}\right)+D f H I_{\lambda}
$$

The methodology we use to calculate $A P E$ for the $G H I$, $D f H I$ and $D N I$ spectral data is the same approach as described in [2] and [3]. Specific details on the method can be obtained by referring to these papers, while an abridged description is given in the following six steps: 1) integrate the spectral irradiance over the wavelength range of $400-1050 \mathrm{~nm}$ to obtain broadband irradiance in units of $\mathrm{W} \mathrm{m}^{-2}$ and filter out instances where irradiance is less than $150 \mathrm{~W} \mathrm{~m}^{-2}, 2$ ) calculate the $A P E$ of the spectrum by dividing the total broadband irradiance by the photon flux density per Eq. [2], 3) for each spectral measurement, bin the spectral irradiance values into $50 \mathrm{~nm}$ bands and integrate to arrive at the broadband irradiance in each bin, 4) calculate the relative contribution, $R_{C}$, of each $50 \mathrm{~nm}$ band to the total irradiance from step 1), 5) bin the $A P E$ values into $0.02 \mathrm{eV}$ groups, and 6) calculate the mean of $R_{C}$ values of each wavelength band and every APE group.

$$
A P E[e V]=\frac{\int_{a}^{b} E(\lambda) d \lambda}{q \int_{a}^{b} \phi(\lambda) d \lambda}
$$

In Eq. [2] $E(\lambda)$ is the spectral irradiance [ $\left.\mathrm{W} \mathrm{m}^{-2} \mathrm{~nm}^{-1}\right], \phi(\lambda)$ is the spectral photon flux density [photons $\mathrm{m}^{-2} \mathrm{~s}^{-1} \mathrm{~nm}^{-1}$ ], and $q$ is the electron charge. The lower integration limit $a=400 \mathrm{~nm}$ and the upper integration limit $b=1050 \mathrm{~nm}$. Note that some authors $[4,5,9]$ calculate $A P E$ over the range of $350 \mathrm{~nm}$ to $1050 \mathrm{~nm}$, which results in $A P E$ values slightly higher than those reported in this paper. The APE parameter does not describe the absolute intensity of the spectrum, but rather the distribution of light within a spectrum. Solar spectra with higher $A P E$ values are said to be 'blue shifted' while a spectra with lower $A P E$ values are considered to be 'red shifted'.
In the second part of this work we quantitatively show the impact the APE parameter has on BIPV performance. To demonstrate this effect we made three single cell coupons in DTU Fotonik's PV prototyping facilities, each of which was laminated with a unique glass superstrate. The common materials used in each coupon are: a $156 \mathrm{~mm}$ by $156 \mathrm{~mm}$ mono-Si cell, ethylene-vinyl acetate (EVA) encapsulant, two bus bars, and a black backsheet. The only material that is changed in each coupon is the type of glass. Two of the glass superstrates have embedded nanostructures that selectively reflect colors in the visible light spectrum. Such glasses are commonly used in BIPV applications to meet the aesthetic standards that are largely required by architects. The two colored glasses we analyze in this work will be referred to as Blue Sample and Gold Sample hereafter. The third coupon uses standard PV glass with low iron content and will be referred to as the Control Sample hereafter.

To assess how these devices perform under varying spectral conditions we measured the external quantum efficiency $(E Q E)$ in a QEXL tester from PV Measurements, USA. The samples were light soaked for $5.5 \mathrm{kWh} \mathrm{m}^{-2}$ prior to measurement. The spectral impact on each device is then determined using the spectral mismatch formula from IEC 60904-7 shown in Eq. 3.

$M M=\frac{\int E_{\text {Ref }}(\lambda) * S R_{\text {Ref }}(\lambda) d \lambda}{\int E_{\text {Meas }}(\lambda) * S R_{\text {Ref }}(\lambda) d \lambda} \frac{\int E_{\text {Meas }}(\lambda) * S R_{\text {DUT }}(\lambda) d \lambda}{\int E_{\text {Ref }}(\lambda) * S R_{\text {DUT }}(\lambda) d \lambda}$

In Eq. $3 E_{R e f}$ is the AM $1.5 \mathrm{G}$ reference spectrum, $E_{\text {meas }}$ is the calculated $G H I_{\lambda}$ from Eq. 1, $S R_{D U T}$ is the spectral response of the test samples, and $S R_{\text {Ref }}$ is the spectral response of the reference device. The measured $E Q E$ data were translated to spectral response using the Plank-Einstein relation and thus used as the $S R_{D U T}$ parameter. A thermopile pyranometer is used as the reference device, $S R_{R e}$; the uniform spectral response of the pyranometer allows Eq. 3 to be simplified in a form equivalent to spectral influence equation proposed in IEC 61853-3 [11]. Another way of looking at Eq. 3 is the dimensionless ratio of photocurrents. It can be described as the difference in photocurrent between the test sample and hypothetical reference at measured spectral conditions, versus the difference in photocurrents at the reference spectral conditions.

IEC 60904-7 requires that the limits of integration in Eq. 3 span the entire wavelength range in which the test sample is active. Since the coupons analyzed in this work have a nonzero response between $330 \mathrm{~nm}$ to $1200 \mathrm{~nm}$, and the spectroradiometers only span the range of $300 \mathrm{~nm}$ to $1100 \mathrm{~nm}$, it is therefore necessary to extend the spectral range. We use the Simple Model of the Atmospheric Radiative Transfer of Sunshine (SMARTS) using inputs of onsite measured ambient temperature, relative humidity and air mass. Similar approaches have been used in previous works to extend the spectral range of silicon detectors [12]. The fit between 
measured and modeled data works well on clear-sky days, but a scaling factor based on the ratio of broadband $D f H I$ to $G H I$ is used for diffuse days. The accuracy of the join is checked by linear regression of short circuit current $\left(I_{S C}\right)$ by total broadband irradiance GHI. Any instances where the deviation from linearity is greater than $2 \%$ are filtered from the data set [13].

\section{APE RESULTS}

The results for the measured $D f H I, D N I$ and calculated $G H I$ datasets are shown in Fig. 2. - Fig. 4. Recall that the y-axis shows the average relative percentage contribution $\left(R_{C}\right)$ of each $50 \mathrm{~nm}$ bin for each $A P E$ group. After filtering out low irradiance conditions (i.e. $G H I<150 \mathrm{~W} \mathrm{~m}^{-2}$ ), and $A P E$ values with less than 20 occurrences, only $40 \%$ of the original data remains, and as such each plot is comprised of 15,761 individual spectral measurements. Note that the legends for the three datasets are not similar in scale due to the different range of $A P E$ values observed for each component of irradiance. The $D f H I$ and $D N I$ components contain the widest range of $A P E$ values: $1.84-2.24 \mathrm{eV}$ and $1.68-1.96 \mathrm{eV}$, respectively. Meanwhile, the GHI component has the narrowest range of $A P E$ values: $1.80-1.94 \mathrm{eV}$. The most frequently occurring $A P E$ value for the $D f H I, D N I$ and $G H I$ components are $1.88 \mathrm{eV}(\mathrm{n}=3395), 1.82 \mathrm{eV}(\mathrm{n}=3604)$, and $1.86 \mathrm{eV}(\mathrm{n}=8222)$, respectively. The mode of $1.86 \mathrm{eV}$ for GHI measurements is consistent with annual GHI measurements previously report for two geographic locations in [2], but not consistent with the AM 1.5G reference spectrum, which has an $A P E$ of $1.84 \mathrm{eV}$ in the $400 \mathrm{~nm}$ to 1050 $\mathrm{nm}$ range analyzed. However, with respect to the DNI measurements, the mode of $1.82 \mathrm{eV}$ is consistent with the $A P E$ of the AM 1.5D spectrum.

The $A P E$ values from the $D N I$ and $G H I$ datasets follow near normal distributions wherein the mean $A P E$ value is equal to or approximately the most frequently occurring values previously mentioned. However, the $A P E$ values of the $D f H I$ dataset show a significant skewness with an overall tendency toward high energy spectral distributions, wherein the mean $A P E$ value of the annual $D f H I$ is $1.96 \mathrm{eV}$. This finding is significant for PV designers in the Northern latitudes where the solar resource is characterized by a significant contribution of diffuse light. In Copenhagen for example, the average monthly clearness index $\mathrm{K}_{\mathrm{T}} \approx 0.4$, which means that only $40 \%$ of the light at the top of the atmosphere reaches the ground in Copenhagen. Even on clear sky days, there are specific PV technologies that could be impacted by such high energy contributions from diffuse light. Such technologies include BIPV installations where North facing (or South facing PV in the southern hemisphere) is installed on the façade, or in bifacial PV systems during moments when the back side of the module receives only the diffuse contribution of light from the sky dome.

The $D f H I$ dataset shows that the contribution of blue light $(400-500 \mathrm{~nm})$ to the total broadband irradiance can change significantly (7-25\%), while the contribution of green light in the $550-600 \mathrm{~nm}$ band is the most consistent $(9-11 \%)$. The DNI dataset shows large fluctuations in the contribution of both high energy $(450-500 \mathrm{~nm})$ and low energy photons $(1000-1050 \mathrm{~nm})$. Finally, the GHI dataset shows a similar shape with that reported in previous studies [2] - [4] with a near constant contribution to broadband irradiance in the 600 - $650 \mathrm{~nm}$ band. In all three irradiance components, the inflection point between blue shifted and red shifted $A P E$ values lies between $550 \mathrm{~nm}$ to $700 \mathrm{~nm}$.

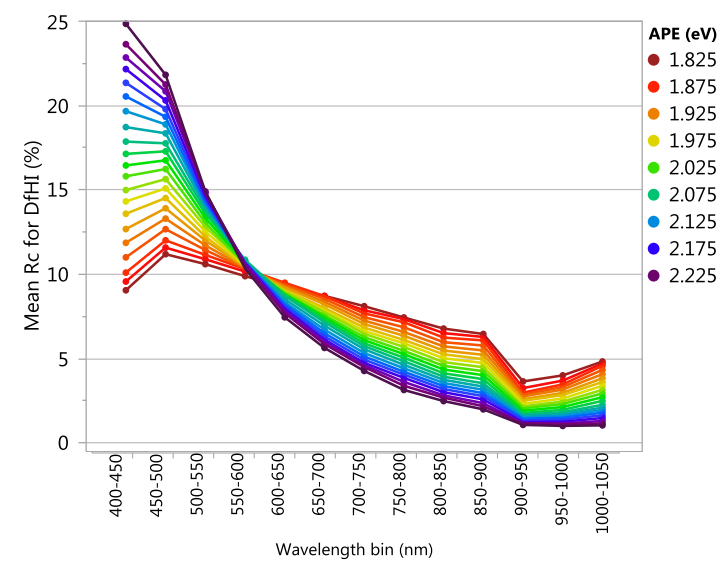

Fig. 2. Relative contribution $\left(\mathrm{R}_{\mathrm{C}}\right)$ in percent of each $50 \mathrm{~nm}$ bin to the total broadband diffuse horizontal irradiance (DfHI). The APE values are grouped every $0.02 \mathrm{eV}$ and span from 1.84 to $2.24 \mathrm{eV}$.

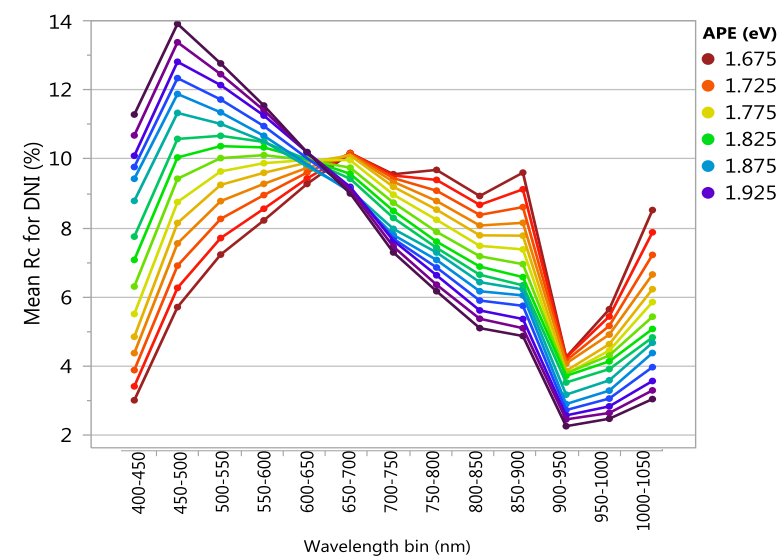

Fig. 3. Relative contribution $\left(\mathrm{R}_{\mathrm{C}}\right)$ in percent of each $50 \mathrm{~nm}$ bin to the total broadband direct normal irradiance (DNI). The APE values are grouped every $0.02 \mathrm{eV}$ and span from 1.68 to $1.96 \mathrm{eV}$. 


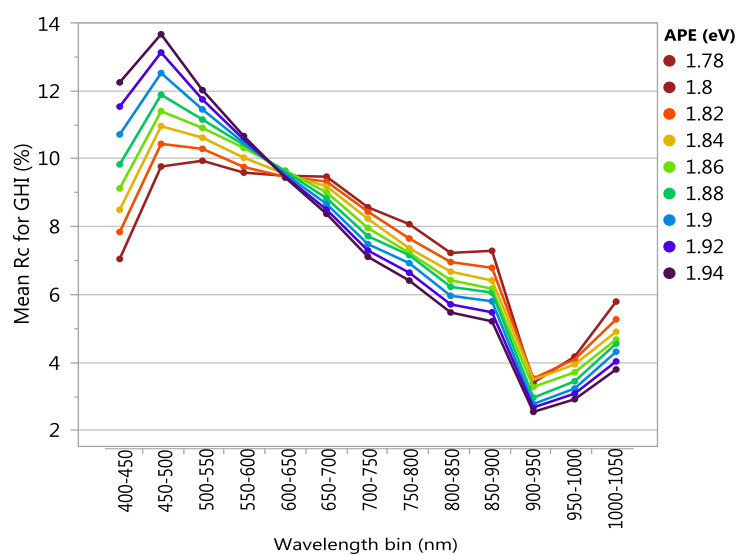

Fig. 4. Relative contribution $\left(\mathrm{R}_{\mathrm{C}}\right)$ in percent of each $50 \mathrm{~nm}$ bin to the total broadband global horizontal irradiance (GHI). The APE values are grouped every $0.02 \mathrm{eV}$ and span from 1.8 to $1.94 \mathrm{eV}$.

The maximum standard deviations of $R_{C}$ for each $A P E$ group and each irradiance component are shown in Fig. 5. Each data point in this chart represents the distributions of 13 $R_{C}$ values (i.e. the 13 wavelength bins) in each $A P E$ group. A statistical analysis of the variation between the three irradiance components reveals that the variation of $R_{C}$ in the $G H I$ dataset is low $(0.29-0.52 \%$, with $95 \%$ confidence), which signifies that each APE group represents few possible spectral distributions despite the $G H I$ data in this case being derived from two separate measurements. This further suggests that the APE values for $G H I$ at this location are indeed representative of a unique spectral distribution.

In Fig. 5, the horizontal green lines near the top and bottom of the green diamonds show the $95 \%$ confidence interval of the mean, and the distributions are considered significantly different when the confidence intervals do not overlap. With this in mind, it becomes clear that the variations in $R_{C}$ values for the DfHI and DNI datasets are nearly identical. Furthermore, the variation in $R_{C}$ in the $D f H I$ and $D N I$ data is significantly higher $(p=0.02)$ than for the GHI dataset. Recall that the $D f H I$ and $D N I$ datasets contain a wider range of $A P E$ values than the $G H I$ dataset, which could contribute to the higher variation observed in $R_{C}$. It is also known that $D N I$ is more sensitive to the effects of aerosols and air mass [14], which could explain the variation in DNI.

The GHI data are presented in tabular form in Table 1 to allow future authors using spectral data from other geographic locations to compare results. Hitherto, comparable data has been reported in the literature from the following six sites: Kusatsu-city, Japan $\left(34.6^{\circ} \mathrm{N}, 135.6^{\circ}\right.$ E) [3], Golden, Colorado, USA $\left(39.7^{\circ} \mathrm{N}, 105.2^{\circ} \mathrm{W}\right)$, Ispra, Italy $\left(45.8^{\circ} \mathrm{N}\right.$, $\left.8.6^{\circ} \mathrm{E}\right)$ [2], Jaén, Spain $\left(37.5^{\circ} \mathrm{N}, 3.5^{\circ} \mathrm{W}\right)$, Madrid, Spain $\left(40.2^{\circ} \mathrm{N}, 3.4^{\circ} \mathrm{W}\right)[4]$, and Roskilde, Denmark $\left(55.7^{\circ} \mathrm{N}, 12.1^{\circ}\right.$ E). The global spectral data from Kusatsu-city, Jaén, and Madrid all showed a max standard deviation in $R_{C}$ less than $0.4 \%$ and the data for Roskilde, Denmark show a maximum of $0.52 \%$.

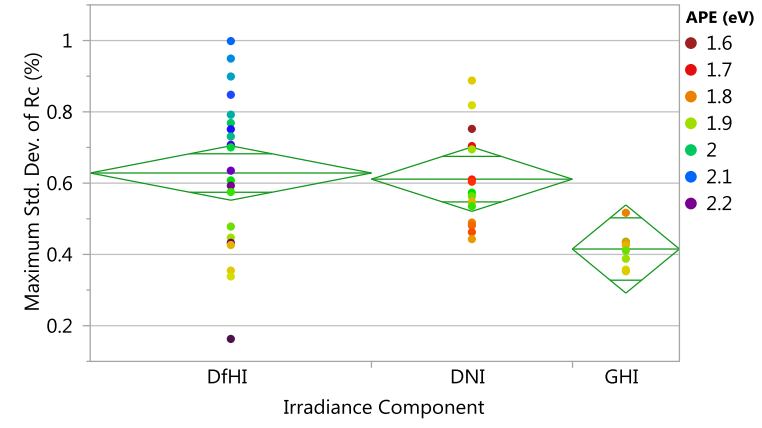

Fig. 5. ANOVA plot for the three irradiance components analyzed. The max standard deviation of the RC values contributing to each APE group are shown. The top and bottom of the green diamonds show the $95 \%$ confidence interval of each distribution's mean.

Although the data from the Golden and Ispra sites show a max standard deviation in $R_{C}$ of as much as $1.3 \%$, these larger standard deviations are only seen at the least frequently occurring $A P E$ values of $1.78 \mathrm{eV}$ or $1.92 \mathrm{eV}$. If these extreme $A P E$ values are excluded, the Golden and Ispra sites show a maximum standard deviation of about $0.7 \%$. Although there are now six sites from around the world whose spectral data essentially show the same result, the question regarding the extent to which mechanisms such as atmospheric conditions and instrument uncertainty drive the deviations in $R_{C}$ must be a subject of on-going investigation. For example, Table 1 shows that the wavelength bin where the highest variation in $R_{C}$ most often occurs is between $900 \mathrm{~nm}$ and $950 \mathrm{~nm}$, which is a region in the spectrum greatly impacted by water absorption.

Fig. 6 shows the annual trends in the $A P E$ broken into the $D N I, D f H I$ and $G H I$ components overlaid with monthly clearness index $K_{T}$ calculated using data from a secondary class pyranometer mounted behind the spectroradiometers (Fig. 1).

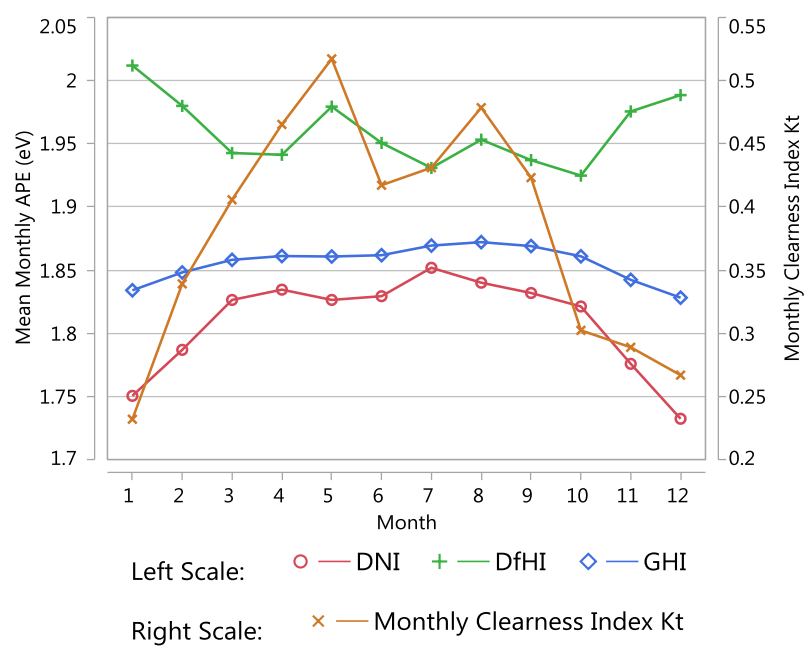

Fig. 6. Overlay of the mean monthly APE for the direct, diffuse and global irradiance components (left scale). The monthly clearness index $\left(\mathrm{K}_{\mathrm{T}}\right)$ (right scale). 
TABLE I

VARIABILITY OF THE RELATIVE CONTRIBUTION (RC) BINNED BY APE - GHI DATASET

\begin{tabular}{|c|c|c|c|c|c|}
\hline $\begin{array}{c}\text { Central APE } \\
\text { Value (eV) }\end{array}$ & $\boldsymbol{\sigma}_{\min }$ & $\boldsymbol{\sigma}_{\text {mean }}$ & $\boldsymbol{\sigma}_{\max }$ & N Samples & $\begin{array}{c}\text { Wavelength bin where } \\
\boldsymbol{\sigma}_{\text {max }} \text { occurs }\end{array}$ \\
\hline 1.80 & 0.12 & 0.26 & 0.52 & 56 & $900-950 \mathrm{~nm}$ \\
\hline 1.82 & 0.09 & 0.23 & 0.43 & 370 & $900-950 \mathrm{~nm}$ \\
\hline 1.84 & 0.10 & 0.21 & 0.43 & 2920 & $900-950 \mathrm{~nm}$ \\
\hline 1.86 & 0.10 & 0.20 & 0.35 & 8222 & $900-950 \mathrm{~nm}$ \\
\hline 1.88 & 0.09 & 0.18 & 0.36 & 3408 & $400-450 \mathrm{~nm}$ \\
\hline 1.90 & 0.09 & 0.20 & 0.39 & 566 & $400-450 \mathrm{~nm}$ \\
\hline 1.92 & 0.08 & 0.17 & 0.41 & 153 & $400-450 \mathrm{~nm}$ \\
\hline 1.94 & 0.10 & 0.18 & 0.44 & 66 & $400-450 \mathrm{~nm}$ \\
\hline
\end{tabular}

Recall that $K_{T}$ is the monthly fraction of broadband insolation $\left[\mathrm{Wh} \mathrm{m}^{-2}\right]$ received on the earth's surface (Roskilde) relative to what is received at the top of the atmosphere (AM0). This parameter therefore represents the prevailing cloud conditions for each month. There appears to be no annual trend of the $D f H I A P E$. In contrast, the $A P E$ of $D N I$ and $G H I$ show clear trends wherein the sunnier spring and summer months result in higher $A P E$ values. The summer months also tend to be the months where the total insolation received is higher. The relationship between cloud cover and $A P E$ is not simple as there is considerable variation in $A P E$ that is not explained by cloud cover or broadband insolation. A more in depth analysis will include the effects of air mass, precipitable water and aerosols on the APE of DNI, DfHI and $G H I$. Such an investigation will be carried out in a future work.

\section{IMPACT OF APE ON BIPV PERFORMANCE}

The measured EQE of the three coupons is shown in Fig. 7. Based on the principle that the perception of color is generally the result of reflected wavelengths that are perceived by the human eye, the $E Q E$ of each coupon behaves as expected. For example, the Blue Sample has low EQE in the $400 \mathrm{~nm}$ to 500 $\mathrm{nm}$ range, which corresponds to blue light in the visible spectrum. Conversely, the Gold Sample does not reflect blue light and as such it has an EQE close to that of the Control Sample in the $400 \mathrm{~nm}$ to $500 \mathrm{~nm}$ range. However, the Gold Sample shows an increasingly low EQE in the $500 \mathrm{~nm}$ to 700 $\mathrm{nm}$ range (green to red) all the way out to $900 \mathrm{~nm}$ due to reflection of light. The secondary y-axis of Fig. 7 shows a normalized $G H I$ spectrum where $A P E$ equals $1.86 \mathrm{eV}$. The spectral data from $300 \mathrm{~nm}$ to $1050 \mathrm{~nm}$ is from the onsite measurements and data beyond $1050 \mathrm{~nm}$ is generated by the SMARTS model. In this sense, the graph also demonstrates the quality of the stitching of these two datasets.

For every valid spectral measurement, the spectral impact on each of the three coupons is calculated per Eq. [2]. Since the spectral mismatch factor $(M M)$ in Eq. [2] is ultimately applied to the broadband data, and since we are estimating the spectral impact on a monthly basis, it is therefore necessary to weight the $M M$ according to the broadband insolation. The weighted spectral impact is calculated by multiplying the $M M$ by the broadband insolation [ $\mathrm{Wh} \mathrm{m}^{-2}$ ] and then dividing this quantity by the broadband insolation. This is the same approach that has been used in [5] and [6]. In this work the spectral impact is only calculated for the GHI dataset. The average monthly impact of the three coupons is plotted as a function of $A P E$ in Fig. 8 below.

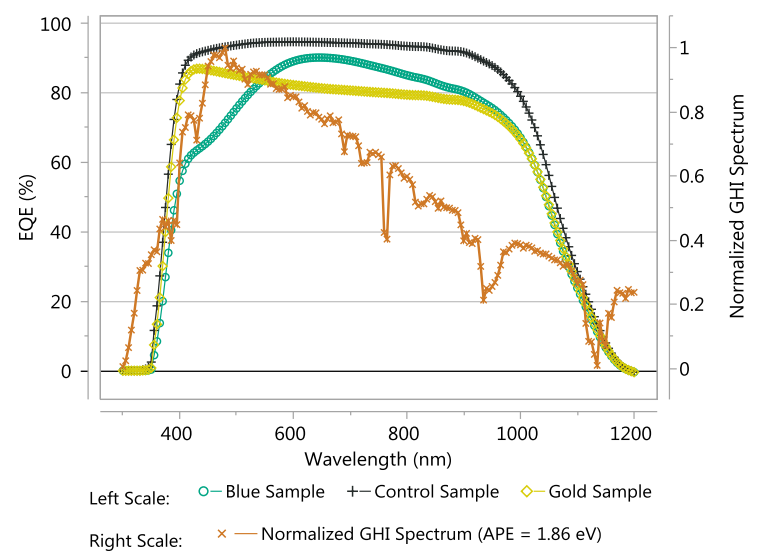

Fig. 7. Overlay of the external quantum efficiency of three mono$\mathrm{Si}$ coupons with different glasses (left scale). The spectral distribution of irradiance when APE $=1.86 \mathrm{eV}$

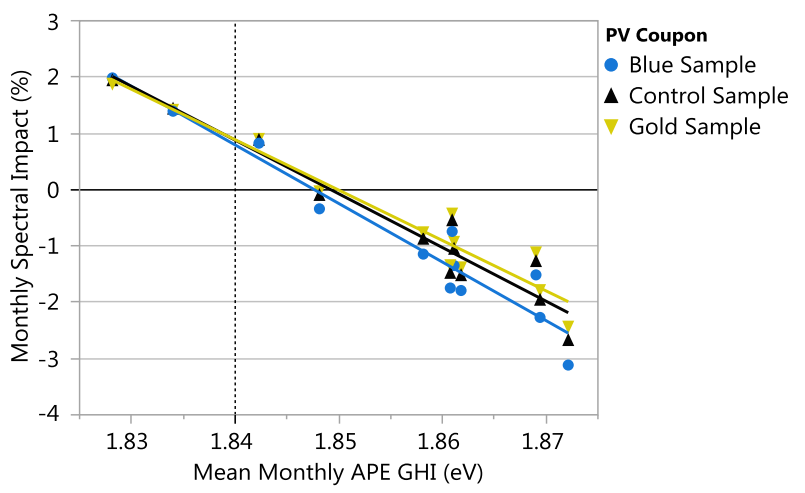

Fig. 8. Regressions of the monthly weighted spectral impact by the average APE for the GHI dataset. 
The $1.84 \mathrm{eV} A P E$ of the AM $1.5 \mathrm{G}$ reference spectrum is shown with the vertical dashed reference line. Recall that as the APE increases, the spectrum becomes increasingly shifted towards blue rich wavelengths. When the spectral impact is greater than zero this indicates that the coupon yielded a spectral gain relative to the photocurrent it would have generated under the AM $1.5 \mathrm{G}$ reference spectrum, and conversely a value less than zero indicates the coupon yielded less photocurrent than it would have under the AM1.5G reference spectrum. With this in mind it becomes clear that the performance of the Blue Sample is more heavily impacted by higher energy spectra than the Control Sample or the Gold Sample. This result makes sense when considering that the blue glass used in the coupon blocks a significant portion of blue light. Similarly, the Gold Sample is least impacted by high energy spectra as the glass used has the highest transmission in the $400 \mathrm{~nm}$ to $500 \mathrm{~nm}$ region. Finally, on an annual basis, the average spectral impacts are $-0.8 \%,-0.6 \%$, and $-0.5 \%$ for the Blue, Control and Gold Samples, respectively.

The results shown in Fig. 8 do not consider the angular dependence of the $E Q E$ as a function of solar incidence angle. Work from [15] has shown that EQE of PV devices can vary greatly with incident angle and therefore a more accurate analysis would consider such effects. Further improvements would be to include spectral data from more than the 12 months that were available for this analysis and an investigation into the non-bijective behavior Fig. 8 . Specifically, the most common occurring $A P E$ value of 1.86 $\mathrm{eV}$ shows a variation in spectral impact of almost $1 \%$. It would be interesting to acquire more $A P E$ data where the monthly average is between, for example, 1.83 to $1.85 \mathrm{eV}$ and observe if there is significant variation in the spectral impact factor at those values as well.

\section{CONCLUSIONS}

One year of spectrally resolved irradiance data for $D N I$, $D f H I$ and $G H I$ components in Denmark has been presented. The $A P E$ of the $G H I$ dataset has been shown to represent spectral distributions with low standard deviations, which is consistent with the findings of previous authors analyzing $G H I$ measurements. In contrast, the $A P E$ values calculated from the $D f H I$ and $D N I$ datasets were characterized by larger variations in spectral distributions and the differences to the GHI dataset were determined statistically significant. The importance of the spectral content of light in BIPV design has been demonstrated. We have shown that the spectral loss on BIPV devices with blue colored glass can be as much as $0.5 \%$ more than BIPV devices with standard glass. And on an annual basis, the average spectral impacts are $-0.8 \%,-0.6 \%$, and $-0.5 \%$ for the Blue glass, Control glass and Gold glass Samples, respectively. The energetic losses primarily occur under high energy spectral distributions, which tend to occur during cloudy sky conditions.

\section{ACKNOWLEDGEMENT}

This work was funded by the Danish Energy Technology Development and Demonstration Programme (EUDP) by the project 64017-05218, EnClose - Smart facade cladding for new buildings and renovation.

\section{REFERENCES}

[1] International Energy Agency (IEA), Trends 2017 in photovoltaics. Report IEA PVPS T1-32:2017, 2017.

[2] M. Norton, A.M. Garcia Amarillo, R. Galleano, "Comparison of solar spectral irradiance measurements using the average photon energy parameter," Solar Energy, vol. 120, pp. 337-344, 2015.

[3] T. Minemoto, Y. Nakada, H. Takahashi, H. Takakura, "Uniqueness verification of solar spectrum index of average photon energy for evaluating outdoor performance of photovoltaic modules," Solar Energy, vol. 83, issue 8, pp. 1294-1299, 2009.

[4] G. Nofuentes, C.A. Gueymard, J. Aguilera, M.D. Perez-Godoy, F. Charte, "Is the average photon energy a unique characteristic of the spectral distribution of global irradiance?", Solar Energy, vol. 149, pp. 32-43, 2017.

[5] D. Dirnberger, G. Blackburn, B. Muller, C. Reise "On the impact of solar spectral irradiance on the yield of different PV technologies,"Solar Energy Materials and Solar Cells, vol. 132, pp. 431-442, 2015.

[6] T. Ishii, K. Otani, A. Itagaki, K. Utsunomiya, "A simplified methodology for estimating solar spectral influence on photovoltaic energy using average photon energy," Energy Science and Engineering, vol. 1, issue 1, pp. 18-26, 2013.

[7] C.N. Jardine, T. Betts, R. Gottschalg, D. Infield, "Influence of spectral effects on the performance of multijunction amorphous silicon cells," in Photovoltaic in Europe Conference, 2002.

[8] JRC International Spectroradiometer Comparison 2017, http://www.intercomparison.eu/

[9] Louwen, A., de Waal, A.C., van Sark, W.G.J.H.M., 2016. "Evaluation of different indicators for representing solar spectral variation", In: Proc 43th IEEE Photovoltaic Specialists Conference, Portland, OR

[10] "IEC 60904-7, Computation of the spectral mismatch correction for measurements of photovoltaic devices.” 2009.

[11] T. Huld, "Presentation of draft of IEC 61853-3," Proc. $7^{\text {th }}$ PV Performance Workshop, Lugano, Switzerland, 2017.

[12] C.R. Osterwald, K.A. Emery, D.R. Myers, and C.J. Riordan, "Extending the Spectral Range of Silicon-Based Direct-Beam Solar Spectral Radiometric Measurements," Proc. 20th IEEE Photovoltaic Specialists Conf., Las Vegas, NV, September 2630, 1988, pp. 1246-1250, IEEE, New York, 1989.

[13] "IEC 60904-10, Methods of linearity measurement." 2010.

[14] C.A. Gueymard, "Irradiance variability and its dependence on aerosols," Proc. SolarPACES Conf., Granada, Spain, 2011

[15] F. Plag, I. Kröger, T. Fey, F. Witt, \& S. Winter "Angulardependent spectral responsivity - Traceable measurements on optical losses in PV devices" Prog. Photovoltaics Res. Appl.,Special Issue Paper, pp. 1-14, 2017. 